\title{
Gas phase infrared spectroscopy of mono- and divanadium oxide cluster cations
}

\author{
Knut R. Asmis ${ }^{\text {a) }}$ and Gerard Meijer \\ Fritz-Haber-Institut der Max-Planck-Gesellschaft, Faradayweg 4-6, D-14195 Berlin, Germany \\ Mathias Brümmer, Cristina Kaposta, Gabriele Santambrogio, and Ludger Wöste \\ Institut für Experimentalphysik, Freie Universität Berlin, Arnimallee 14, D-14195 Berlin, Germany \\ Joachim Sauer ${ }^{\text {b) }}$ \\ Institut für Chemie, Humboldt-Universität Berlin, Unter den Linden 6, D-10099 Berlin, Germany
}

(Received 3 December 2003; accepted 6 January 2004)

\begin{abstract}
The vibrational spectroscopy of the mono- and divanadium oxide cluster cations $\mathrm{VO}_{1-3}{ }^{+}$and $\mathrm{V}_{2} \mathrm{O}_{2-6}{ }^{+}$is studied in the region from 600 to 1600 wave numbers by infrared photodissociation of the corresponding cluster cation-helium atom complexes. The comparison of the experimental depletion spectra with the results of density functional calculations on bare vanadium oxide cluster cations allows for an unambiguous identification of the cluster geometry in most cases and, for $\mathrm{VO}_{1-3}{ }^{+}$and $\mathrm{V}_{2} \mathrm{O}_{5,6}{ }^{+}$, also of the electronic ground state. A common structural motif of all the studied divanadium cluster cations is a four-membered $\mathrm{V}-\mathrm{O}-\mathrm{V}-\mathrm{O}$ ring, with three characteristic absorption bands in the 550-900 wave number region. For the $\mathrm{V}-\mathrm{O}-\mathrm{V}$ and $\mathrm{V}=\mathrm{O}$ stretch modes the relationship between vibrational frequencies and $\mathrm{V}-\mathrm{O}$ bond distances follows the Badger rule.

(C) 2004 American Institute of Physics. [DOI: 10.1063/1.1650833]
\end{abstract}

\section{INTRODUCTION}

Vanadium oxides are important in many technological applications, ${ }^{1}$ e.g., in heterogeneous catalysis, semiconductors, optical devices, and coatings. The rational design of supported vanadium oxide catalysts remains difficult, ${ }^{2}$ because of the lack of a consistent model that quantitatively explains the structure/reactivity relationship at a molecular scale. Progress is being made by applying spectroscopic methods in situ ${ }^{3}$ during catalytic operation, but the identification and characterization of the active sites with currently available surface science techniques remains challenging. As many active catalysts contain vanadium oxide highly dispersed on different oxide supports, important contributions can come from gas phase cluster studies.

The formation of isolated vanadium oxide cluster cations and anions as well as their reactivity with various reactants has been studied under well-controlled conditions as a function of their size. ${ }^{4-8}$ While mass spectrometry has become a standard technique to identify charged reactants and products and to provide information about their composition, the determination of their geometric structures remains an experimental challenge. The lack of structural knowledge together with the lack of thermochemical data so far has limited the understanding of the cluster reactivity. Attempts to predict structures from observed reactivity patterns, ${ }^{6}$ for example, are in conflict with later predictions from reliable quantum chemical calculations. Anion photoelectron spectroscopy has proven very useful in characterizing the structure of small,

\footnotetext{
a) Author to whom correspondence should be addressed; electronic mail: asmis@fhi-berlin.mpg.de

b) Author to whom correspondence should be addressed; electronic mail: sek.qc@chemie.hu-berlin.de
}

neutral vanadium oxide clusters; ${ }^{5}$ the spectra of the larger clusters $^{9}$ are too congested to resolve any vibrational structure. The first IR spectra of individual vanadium oxide cluster cations were recently obtained from IR photodissociation studies using a tunable free electron laser..$^{10-12}$

Quantum mechanical methods, in particular methods based on density functional theory (DFT), have proven very useful in identifying the molecular structure of metal oxide clusters in the gas phase based on a comparison of calculated and measured vibrational frequencies. ${ }^{13}$ The electronic structure of transition metal oxides and other transition metal compounds is more difficult to calculate than main group compounds because partially filled $d$ shells and the weak coupling of $d$ electrons on different transition metal atoms lead to many nearly degenerate electronic states. Tests have shown ${ }^{14,15}$ that structures of the same quality as for main group compounds can be obtained for transition metal compounds if the B3LYP hybrid density functional ${ }^{16}$ is used. DFT predictions for structures of vanadium oxide clusters of increasing size have first been made for neutral clusters and cluster anions. ${ }^{17,18}$ Shortly after this, predictions have also been made for the corresponding cations. ${ }^{19-22}$ Later, the methodology first used for cluster anions ${ }^{17}$ has been applied to cationic clusters and their reaction products with ethylene ${ }^{7,11}$ Reliable structure prediction is also complicated by the large number of low energy isomers in combination with many low lying electronic states. Several previous computational studies on small vanadium oxide cluster cations, for example, do not agree on the lowest electronic state and the global minimum structure, even though they apply very similar computational techniques. ${ }^{7,19-21}$

We recently reported a novel method ${ }^{12}$ of measuring IR spectra of cluster ions by photodissociation of cluster ion- 
rare gas complexes formed in a cold ion trap. In contrast to photodissociation of the bare cluster ion predissociation of the "messenger atom" complex bears several important advantages. For example, the number of adsorbed photons needed to fragment the complex is considerably smaller (and often equal to one) and, more importantly, independent of the dissociation energy of the bare cluster ion. This ensures that structural isomers can be detected with the same efficiency. The present study combines this technique with a systematic DFT study in order to determine the structure of mono- and divanadium oxide cluster cations. The IR depletion spectra are compared to the DFT predictions for different low lying isomers and/or electronic states, leading to an identification of the ground state even if a global optimization method is not used.

\section{EXPERIMENT}

The present experiments were carried out on a previously described tandem mass spectrometer-ion trap system. ${ }^{10}$ Briefly, vanadium oxide clusters are prepared by a pulsed laser vaporization source. The output of a $\mathrm{Nd}$ :YAG laser (Quantel Brilliant Ultra), operated at $20 \mathrm{~Hz}$, is focused on a rotating 6-mm-diam vanadium rod (Alfa Aesar, 99.5\% purity). The vanadium atom containing plasma is entrained in a pulse of $0.5 \% \mathrm{O}_{2}$ seeded in He carrier gas, expanded through a clustering channel and passed through a skimmer. The beam of positive ions is collimated in a radio frequency ( $\mathrm{rf}$ ) decapole ion guide and then guided into the first rf quadrupole mass filter, which is typically operated at unit resolution. Mass-selected cluster ions are guided into a cooled, He-filled ( $\sim 0.02$ mbar) rf hexadecapole ion trap, where they are accumulated and thermalized to the ambient temperature $(\sim 20 \mathrm{~K})$ through collisions with the He buffer gas (Linde, He 6.0). Under these conditions the formation of cluster ionrare gas atom complexes by three-body association is observed.

$$
\mathrm{V}_{x} \mathrm{O}_{y}{ }^{+} \cdot \mathrm{He}_{n-1}+2 \mathrm{He} \rightleftarrows \mathrm{V}_{x} \mathrm{O}_{y}{ }^{+} \cdot \mathrm{He}_{n}+\mathrm{He}, \quad n=1,2, \ldots
$$

as was previously reported ${ }^{12}$ for the monovanadium oxide cluster cations. The ion concentrations are determined by the rates of the forward and the backward reaction, which depend on temperature and pressure of the He buffer gas.

IR photodissociation spectra are obtained by photoexcitation of the trapped ions with pulsed radiation from the "free electron laser for infrared eXperiments" (FELIX), ${ }^{23}$ which is operated at $5 \mathrm{~Hz}$. A measurement cycle is initiated by the trigger signal of the previous FELIX pulse and the ion trap is allowed to fill with mass-selected ions for a fixed time $t_{\text {fill }}$. Next, the ions are allowed to thermalize, which is assumed to proceed on a time scale of up to a few milliseconds. Then, the accumulated, cooled ions are irradiated inside the ion trap. Directly after FELIX fires, all ions are extracted and the mass-selected ion yield is monitored. This cycle is repeated multiple times (3-10 times for the present experiments) and then FELIX is set to the next wavelength. Resonant absorption of IR radiation by the ion complexes leads to vibrational predissociation of the complexes. Consequently, the ion concentration of the (absorbing) complex decreases and that of the bare ion increases temporarily, until the system is able to dissipate all the absorbed energy and return to equilibrium. Thus, if the rate of reformation is slow enough, the infrared spectroscopy of the parent ions $\mathrm{V}_{x} \mathrm{O}_{y}{ }^{+}$ can be studied by mass-selectively monitoring changes in the $\mathrm{V}_{x} \mathrm{O}_{y}{ }^{+} \cdot \mathrm{He}_{n}$ ion yield as a function of photon wavelength directly after irradiation with a tunable IR source. ${ }^{12}$ The dependence of the dissociation rate on the initially excited vibrational mode is assumed to be negligible, because, under the present experimental conditions, there is sufficient time (microseconds or more) for the efficient redistribution of the excitation energy. Ideally, with $t_{\text {fill }}$ less than $200 \mathrm{~ms}$, the experiment can make use of the FELIX repetition rate of $5 \mathrm{~Hz}$. In practice, longer filling times proved to yield superior signal statistics. An acquisition time $t_{\text {fill }}=600 \mathrm{~ms}$ was used throughout the experiments described here.

In the present study overview spectra are measured in the region from 6 to $16 \mu \mathrm{m}$ with a step size of $0.1 \mu \mathrm{m}$. Spectra with smaller step sizes and longer accumulation times are then measured in those spectral regions, where signal was observed. The output of FELIX is introduced into the ion trap region through a $\mathrm{ZnSe}$ window, a $50 \mathrm{~cm}$ focal length $\mathrm{KBr}$ lens, and a 5-mm-thick $\mathrm{KBr}$ window. Focusing of the FELIX beam is required to avoid light scattering off the ion trap exit and entrance lenses. The transmission of the $\mathrm{KBr}$ optics is nearly wavelength independent in the region studied. The transmission of the $\mathrm{ZnSe}$ window decreases considerably at longer wavelengths. The accuracy of the determined vibrational frequencies is generally within $1 \%$ of the central wavelength. The accuracy of the relative depletion intensities is less well defined, mainly due to the nonmonotonic variation of the FELIX beam intensity, bandwidth, and waist size with wavelength. We did not correct for any of these effects and estimate that our relative intensities vary within $10 \%$ between 1200 and $700 \mathrm{~cm}^{-1}$ and to a larger extent in the region below $700 \mathrm{~cm}^{-1}$.

\section{COMPUTATIONAL METHODS}

All calculations are carried out using the TURBOMOLE suite of programs. ${ }^{24}$ The B3LYP hybrid functional ${ }^{16} \mathrm{em}-$ ployed combines Becke's 1988 nonlocal exchange ${ }^{25}$ with Hartree-Fock exchange along with the Lee-Yang-Parr ${ }^{26}$ correlation functional. Note that other implementations ${ }^{27}$ of the B3LYP functional use a slightly different formulation of the Vosko-Wilk-Nusair (VWN) local correlation functional. ${ }^{28}$ The TZVP basis sets applied are the triple-zeta valence basis sets developed by Ahlrichs and co-workers ${ }^{29}$ augmented by polarization functions, a $d$ set for oxygen and a $p$ set for vanadium. ${ }^{30}$ Harmonic vibrational frequencies are obtained from second analytic derivatives. ${ }^{31}$ Structure optimizations use tight convergence criteria. Structures are optimized until Cartesian gradients are smaller than $1 \times 10^{-4}$ Hartree/Bohr and the energy change smaller than $1 \times 10^{-6}$ Hartree. The self-consistent field convergence criterion is 1 $\times 10^{-7}$ Hartree for the energy and $1 \times 10^{-7}$ a.u. for the rootmean square of the density.

It is known that B3LYP vibrational frequencies are systematically too large (see, e.g., Refs. 32 and 33) and, therefore, agreement with observed frequencies can be improved 
TABLE I. Frequency scaling factors for fundamental vibrations and rootmean-square deviation (rms) derived from a least squares fit of frequencies.

\begin{tabular}{lccc}
\hline \hline & No. of data & Scale factor & $\mathrm{rms}^{\left(\mathrm{cm}^{-1}\right)}$ \\
\hline (1a) Vanadyl modes only & & \\
(1b) V-O-V modes only & 10 & 0.9167 & 13 \\
(2) All modes $^{\mathrm{a}}$ & 14 & 0.9832 & 26 \\
Ref. 32 & 24 & 0.9429 & 35 \\
Ref. 33 & 1066 & 0.9614 & 34 \\
\hline \hline
\end{tabular}

${ }^{\text {aPresent study. }}$

by scaling. Scaling accounts for both anharmonicities (calculated harmonic wave numbers are compared to observed fundamentals including anharmonicities) and systematic errors of the calculated harmonic force constants. For the systems studied anharmonicity effects are expected to be small. We use 24 experimental vibrational frequencies of $\mathrm{VO}^{+}(1)$, $\mathrm{VO}_{2}^{+}(2), \mathrm{V}_{2} \mathrm{O}_{2}^{+}(2), \mathrm{V}_{2} \mathrm{O}_{3}^{+}(4), \mathrm{V}_{2} \mathrm{O}_{4}^{+}(5), \mathrm{V}_{2} \mathrm{O}_{5}^{+}(5)$, and $\mathrm{V}_{2} \mathrm{O}_{6}{ }^{+}(5)$. The two unassigned modes in $\mathrm{VO}_{3}{ }^{+}$and the superoxo mode in $\mathrm{V}_{2} \mathrm{O}_{6}{ }^{+}$are not used. Following the procedure described by Scott and Radom, ${ }^{32}$ two different types of scaling are done: (1) Individual scaling for two groups of frequencies, (a) vanadyl stretch vibrations (10 values) and (b) $\mathrm{V}-\mathrm{O}-\mathrm{V}$ stretch and all other vibrations below $900 \mathrm{~cm}^{-1}$ (14 values). (2) Global scaling using all 24 frequencies. Table I shows the results. The scale factors obtained and the root-mean-square deviations of the scaled frequencies fall into the known ranges. ${ }^{32,33}$

\section{RESULTS}

Optimized B3LYP/TZVP geometries of selected monoand divanadium oxide cluster cations are shown in Fig. 1 and their vibrational frequencies are listed in Table II. Infrared photodissociation spectra of the vanadium oxide cluster cations $\mathrm{VO}_{1-3}{ }^{+}$and $\mathrm{V}_{2} \mathrm{O}_{2-6}{ }^{+}$, measured by monitoring the depletion of the respective cluster ion- $\mathrm{He}_{n}$ complex $(n=1$, 2, or 3), are shown in Figs. 2-4. Experimental vibrational frequencies (band centers) are listed in Table II. $\mathrm{He}_{n>1}$ complexes were monitored, whenever the depletion signal of the $\mathrm{He}_{1}$ complex was weak or completely masked either due to partial dissociation of $\mathrm{He}_{n>1}$ complexes or rapid reformation dynamics. In all cases the influence of the He atoms on the vibrational frequency is assumed to be small, i.e., on the order of a few wave numbers or less. Rotationally resolved vibrational predissociation experiments on proton-bound $\mathrm{He}$ complexes revealed redshifts up to $15 \mathrm{~cm}^{-1}$ for hydrogen stretching motions, corresponding to less than $0.5 \%$ of the fundamental frequency. ${ }^{34}$ Due to the considerably higher reduced mass and lower vibrational frequency of the modes considered here, the frequency shift should be comparably smaller. For $\mathrm{V}_{2} \mathrm{O}_{2}{ }^{+}$the signal level was very low and the spectra of two different complexes $(n=2$ and $n=3)$ were summed. The simulated spectra are based on globally scaled harmonic frequencies and relative intensities determined by B3LYP/TZVP calculations, and were convoluted with a Gaussian line shape function, with a width that increases linearly with increasing frequency, in order to correct for the wavelength dependent bandwidth of FELIX. The experimen- tal data are plotted against a logarithmic scale to aid in the comparison to the simulated absorption spectra. According to Lambert-Beer's law, the logarithm of the relative depletion $\left(I / I_{0}\right)$ is proportional to the absorption coefficient. Furthermore, it is assumed that if a photon is absorbed, it always leads to dissociation with probability that is independent of wavelength. Binding energies of $\mathrm{He}$ atoms to ionic complexes $^{35}$ are on the order of a few hundred wave numbers or less and thus a single IR photon should be sufficient to dissociate the ion-He atom complexes studied here.

\section{$\mathrm{VO}^{+}$}

The IR depletion spectrum of $\mathrm{VO}^{+} \cdot \mathrm{He}$ (Fig. 2, left) reveals a single band at $1053 \mathrm{~cm}^{-1}$. Upon closer inspection the band shows additional structure, a double minimum feature, which is attributed to the influence of molecular rotations discussed elsewhere in more detail. ${ }^{12}$ The center of the band remains nearly unchanged in the spectra of the $\mathrm{VO}^{+} \cdot \mathrm{He}_{2}$ $\left(1053 \mathrm{~cm}^{-1}\right)$ and $\mathrm{VO}^{+} \cdot \mathrm{He}_{3}\left(1054 \mathrm{~cm}^{-1}\right)$ complexes (not shown), confirming that the He atoms have a negligible influence on the $\mathrm{V}-\mathrm{O}$ stretching frequencies. The position of the band center is in good agreement with, but significantly more accurate than, the value obtained for the ${ }^{3} \Sigma^{-}$ground state of bare $\mathrm{VO}^{+}$using photoelectron spectroscopy (1060 $\left.\pm 40 \mathrm{~cm}^{-1}\right){ }^{36}$ The recent high-level ab initio calculations (multi-reference average coupled pair functional, MR-ACPF, with basis set extrapolation) of Pykavy and van Wüllen ${ }^{37}$ for bare $\mathrm{VO}^{+}$yield $1058 \mathrm{~cm}^{-1}$. Our B3LYP/TZVP frequency $\left(\nu_{\text {scaled }}=1032 \mathrm{~cm}^{-1}\right)$ is in reasonable agreement with these results, as is the calculated bond length $\left(r_{e}=1.55 \AA\right)$, which was determined experimentally $\left(r_{0}=1.56 \AA\right)$ from rotationally resolved pulsed field ionization spectra. ${ }^{38}$

\section{$\mathrm{VO}_{2}{ }^{+}$}

Two bands are observed in the depletion spectrum of $\mathrm{VO}_{2}{ }^{+} \cdot \mathrm{He}_{2}$ (Fig. 2, right) at 1017 and $990 \mathrm{~cm}^{-1}$ with relative intensities of $1-3$. Both, the intensity ratio and the splitting of the two bands, are reproduced well by the B3LYP/TZVP calculations, confirming the bent ${ }^{1} A_{1}$ ground state for $\mathrm{VO}_{2}{ }^{+}$, originally proposed by Harvey et al. ${ }^{8}$ The two bands are assigned to the symmetric $\left(\nu_{\text {scaled }}=1038 \mathrm{~cm}^{-1}\right)$ and antisymmetric $\left(\nu_{\text {scaled }}=1011 \mathrm{~cm}^{-1}\right)$ stretch mode, respectively. The energy of the bending mode, predicted at $\nu_{\text {scaled }}=445 \mathrm{~cm}^{-1}$ with a relative intensity of $3 \%$, is too small to be observed in the present spectra. The spectrum ${ }^{20}$ of the lowest triplet state, an ${ }^{3} A^{\prime \prime}$ state $156 \mathrm{~kJ} / \mathrm{mol}$ above the ${ }^{1} A_{1}$ ground state, with vibrational frequencies of 1171 and $690 \mathrm{~cm}^{-1}$, clearly does not match the experimental spectrum.

\section{$\mathrm{VO}_{3}^{+}$}

The depletion spectrum of $\mathrm{VO}_{3}{ }^{+} \cdot \mathrm{He}_{2}$ (Fig. 3, left) shows two bands. The most intense feature is found at 1069 $\mathrm{cm}^{-1}$. The second peak lies $32 \mathrm{~cm}^{-1}$ lower in energy and is roughly half as intense. Overview scans down to $625 \mathrm{~cm}^{-1}$ (not shown) revealed no additional signal at lower photon energies. The lowest electronic state predicted by our B3LYP calculations is the open-shell ${ }^{3} A^{\prime \prime}$ state with an oxovanadium $(\mathrm{V})-\eta^{2}$-superoxide structure, also found in the 


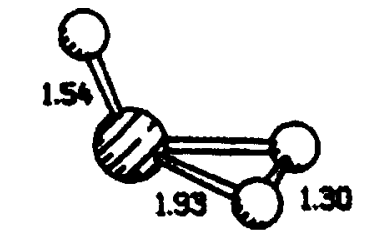

$\eta^{2}$-Superoxo $\mathrm{C}_{\mathrm{s}}{ }^{3} \mathrm{~A}^{\prime \prime}$

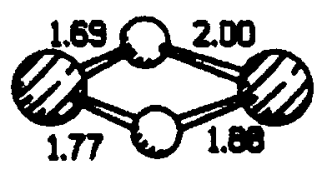

$\mathrm{C}_{5}-{ }^{2} \mathrm{~A}^{\prime}$

$\left({ }^{6} A^{\prime} 2.0\right)$

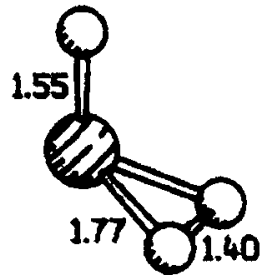

$C_{5}{ }^{1} A^{\prime}(57.9)$

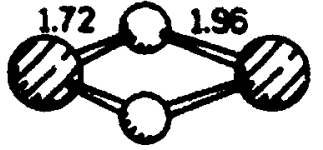

$\mathrm{C}_{2 \mathrm{v}^{-}}{ }^{2} \mathrm{~A}_{2}$ (11.7)

$\left({ }^{6} A_{2} 11.9\right)$

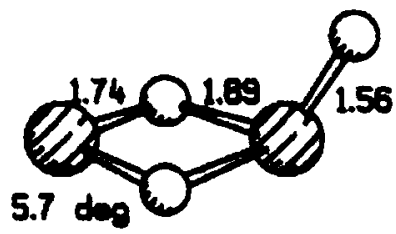

$C_{8}{ }^{2} A^{\prime}$

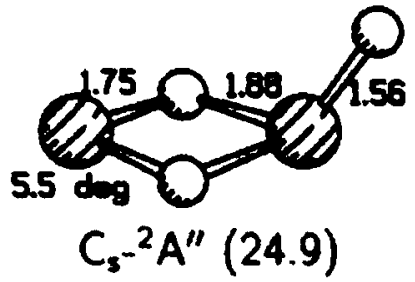

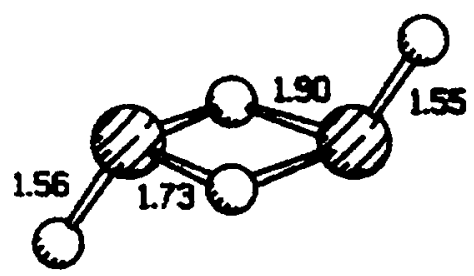

Trans $C_{s}{ }^{2} A^{\prime}$

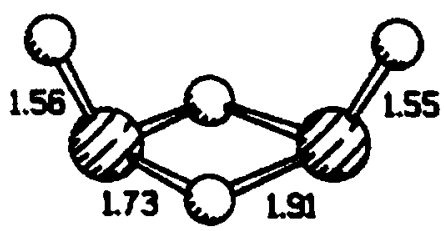

Cis $C_{s}-{ }^{2} A^{\prime}(19.5)$

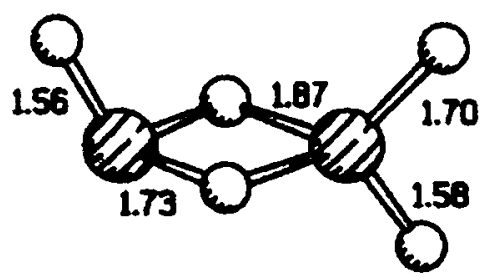

$C_{s}-A^{\prime}$

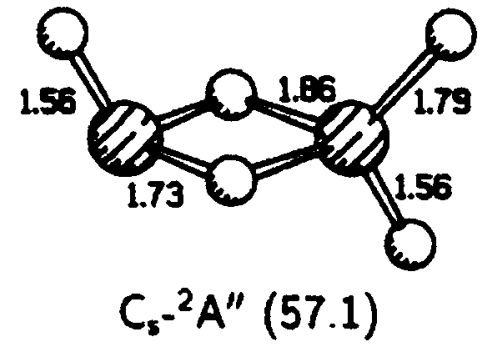

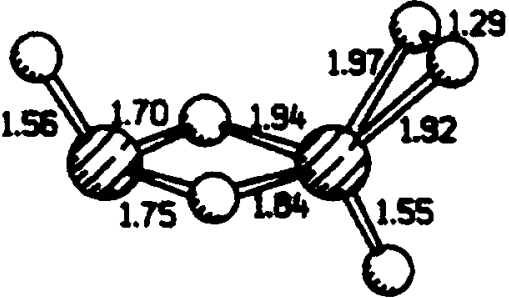

$\eta^{2}$-Superoxo Trans $\mathrm{C}_{1}{ }^{2} \mathrm{~A}$

(Cis 7.7)

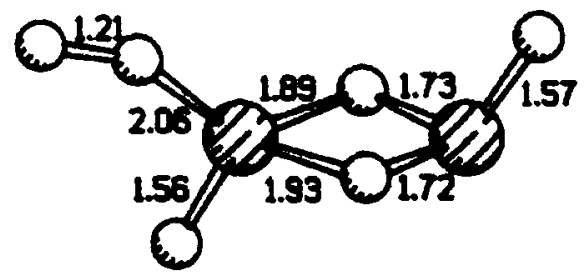

$\mathrm{O}_{2}$-complex Trans $\mathrm{C}_{1}{ }^{2} \mathrm{~A}(45.5)$

(Cis 62.0)

FIG. 1. B3LYP/TZVP optimized structures of selected mono- and divanadium oxide cluster cations. Two structures are shown for each cluster, one of the electronic ground state (top) and the other of an energetically low-lying isomer (bottom). Bond lengths are in $\AA$, bond angles in degrees, and relative energies (in parentheses) with respect to the ground state are in $\mathrm{kJ} / \mathrm{mol}$. The structures of $\mathrm{VO}^{+}$and $\mathrm{VO}_{2}{ }^{+}$are shown in Fig. 2.

previous calculations by Koyanagi et al. ${ }^{19}$ Another study ${ }^{20}$ proposed an ${ }^{1} A^{\prime}$ ground state, but did not consider the ${ }^{3} A^{\prime \prime}$ state of the $\eta^{2}$-superoxo structure. We find this ${ }^{1} A^{\prime}$ state $57.9 \mathrm{~kJ} / \mathrm{mol}$ above the ${ }^{3} A^{\prime \prime}$ ground state. Both states have similar geometries (see Fig. 1), but characteristically different IR spectra (see Fig. 3). The dioxo group in the ${ }^{1} A^{\prime}$ state has larger $\mathrm{O}-\mathrm{O}$ and smaller $\mathrm{OV}-\mathrm{O}_{2}$ bond lengths, but a stronger redshift of the $\mathrm{O}-\mathrm{O}$ stretch, $1051 \mathrm{~cm}^{-1}$ compared to $1126 \mathrm{~cm}^{-1}$ in the ${ }^{3} A^{\prime \prime}$ state. Moreover, the spectrum of the ${ }^{1} A^{\prime}$ state shows several peaks at low photon energies. Summarizing, we find significantly better agreement between the experimental and calculated spectra of the ground electronic state $\left({ }^{3} A^{\prime \prime}\right)$ than for the lowest singlet state $\left({ }^{1} A^{\prime}\right)$. The assignment of the individual bands, one to the vanadyl- and the other to the oxo-mode, is left open, because the predicted intensity ordering does not match the experimental spectrum.

$\mathrm{V}_{2} \mathrm{O}_{2}^{+}$

In contrast to the spectra of the monovanadium oxide cluster cations discussed above, the depletion spectra of $\mathrm{V}_{2} \mathrm{O}_{2}{ }^{+} \cdot \mathrm{He}_{2,3}$ (Fig. 3, center) do not show any features above $900 \mathrm{~cm}^{-1}$, but rather two bands of similar intensity are found at lower photon energies, namely at 833 and $724 \mathrm{~cm}^{-1}$. 
TABLE II. Experimental $\left(v_{\text {expt }}\right)$, calculated $\left(v_{\text {B3LYP }}\right)$, and scaled $\left(v_{\text {scaled }}\right)$ vibrational frequencies, relative intensities (in parentheses), and frequency difference $\Delta v=v_{\text {scaled }}-v_{\text {expt }}$ for mono- and divanadium oxide cluster cations. All frequencies are in wave numbers. Experimental frequencies are based on the IR depletion spectra of the corresponding $\mathrm{V}_{x} \mathrm{O}_{y}^{+} \cdot \mathrm{He}_{n}$ cluster ions. Theoretical values are determined by B3LYP/TZVP calculations. Scaled frequencies are calculated using the individual scaling factors (1a,b in Table I).

\begin{tabular}{|c|c|c|c|c|c|c|c|}
\hline \multicolumn{2}{|c|}{ Experiment } & \multicolumn{6}{|c|}{ B3LYP calculations } \\
\hline System & $v_{\text {expt }}$ & State & $v_{\mathrm{B} 3 \mathrm{LYP}}$ & Sym. & Type & $v_{\text {scaled }}$ & $\Delta v$ \\
\hline $\mathrm{VO}^{+} \cdot \mathrm{He}$ & 1053 & ${ }^{3} \Sigma^{-}$ & $1125(1.00)$ & $a_{1}$ & Vanadyl & 1032 & -21 \\
\hline \multirow[t]{2}{*}{$\mathrm{VO}_{2}^{+} \cdot \mathrm{He}_{2}$} & 1017 & ${ }^{1} A_{1}$ & $1133(0.13)$ & $a_{1}$ & Vanadyl & 1038 & +21 \\
\hline & 990 & & $1103(1.00)$ & $b_{1}$ & Vanadyl & 1011 & +21 \\
\hline \multirow[t]{2}{*}{$\mathrm{VO}_{3}^{+} \cdot \mathrm{He}_{2}$} & $1069^{\mathrm{a}}$ & ${ }^{3} A^{\prime \prime}$ & $1228(0.52)$ & $a^{\prime}$ & Oxо & $1126^{\mathrm{b}}$ & \\
\hline & $1037^{\mathrm{a}}$ & & $1161(1.00)$ & $a^{\prime}$ & Vanadyl & 1064 & \\
\hline \multirow[t]{3}{*}{$\mathrm{V}_{2} \mathrm{O}_{2}^{+} \cdot \mathrm{He}_{2,3}$} & 833 & ${ }^{2} A^{\prime}$ & $849(1.00)$ & $a^{\prime}$ & Ring & 835 & +2 \\
\hline & 724 & & $712(0.98)$ & $a^{\prime}$ & Ring & 700 & -24 \\
\hline & & & $575(1.32)$ & $a^{\prime}$ & Ring & 565 & \\
\hline \multirow[t]{4}{*}{$\mathrm{V}_{2} \mathrm{O}_{3}^{+} \cdot \mathrm{He}_{3}$} & 1044 & ${ }^{2} A^{\prime}$ & $1127(0.63)$ & $a^{\prime}$ & Vanadyl & 1033 & -11 \\
\hline & 803 & & $823(0.46)$ & $a^{\prime}$ & Ring & 809 & +6 \\
\hline & 765 & & $718(0.62)$ & $a^{\prime \prime}$ & Ring & 706 & -59 \\
\hline & 666 & & $638(1.00)$ & $a^{\prime}$ & Ring & 627 & -39 \\
\hline \multirow[t]{5}{*}{$\mathrm{V}_{2} \mathrm{O}_{4}^{+} \cdot \mathrm{He}_{3}$} & 1049 & ${ }^{2} A^{\prime}$ & $1135(0.19)$ & $a^{\prime}$ & Vanadyl & 1041 & -8 \\
\hline & 1029 & & $1116(1.00)$ & $a^{\prime}$ & Vanadyl & 1023 & -6 \\
\hline & 794 & & $844(0.43)$ & $a^{\prime}$ & Ring & 830 & +36 \\
\hline & 776 & & $774(0.47)$ & $a^{\prime \prime}$ & Ring & 761 & -15 \\
\hline & 594 & & $637(0.75)$ & $a^{\prime}$ & Ring & 627 & +33 \\
\hline \multirow[t]{6}{*}{$\mathrm{V}_{2} \mathrm{O}_{5}^{+} \cdot \mathrm{He}$} & 1034 & ${ }^{2} A^{\prime}$ & $1130(0.52)$ & $a^{\prime}$ & Vanadyl & 1036 & +2 \\
\hline & 911 & & $1005(0.54)$ & $a^{\prime}$ & Vanadyl & 921 & +10 \\
\hline & 815 & & $850(0.66)$ & $a^{\prime}$ & Ring & 835 & 20 \\
\hline & 738 & & $749(0.46)$ & $a^{\prime \prime}$ & Ring & 736 & -2 \\
\hline & 657 & & $679(1.00)$ & $a^{\prime}$ & Ring & 668 & 11 \\
\hline & & & $597(0.00)$ & $a^{\prime}$ & $\mathrm{V}-\mathrm{O}$ & 587 & \\
\hline \multirow[t]{6}{*}{$\mathrm{V}_{2} \mathrm{O}_{6}^{+} \cdot \mathrm{He}$} & 1160 & ${ }^{2} A^{\prime}$ & $1246(0.31)$ & $a$ & Oxo & $1142^{\mathrm{b}}$ & -18 \\
\hline & 1060 & & $1149(0.34)$ & $a$ & Vanadyl & 1054 & -6 \\
\hline & 1028 & & $1121(0.80)$ & $a$ & Vanadyl & 1028 & 0 \\
\hline & 836 & & 873 (0.66) & $a$ & Ring & 859 & 23 \\
\hline & 751 & & $765(0.37)$ & $a$ & Ring & 752 & +1 \\
\hline & 673 & & 677 (1.00) & $a$ & Ring & 665 & -8 \\
\hline
\end{tabular}

${ }^{\mathrm{a}}$ Not assigned.

${ }^{\mathrm{b}}$ Scaled with vanadyl scaling factor.

Therefore the presence of vanadyl (or oxo) groups, which would be expected in the region above $900 \mathrm{~cm}^{-1}$, can be excluded. The width of the observed bands is somewhat larger than for the other systems studied. This is a result of the low parent ion signal level, which we compensated by increasing the FELIX power and thus also its bandwidth. Satisfactory agreement is found with the simulated IR spectra of the lowest energy isomer, an ${ }^{2} A^{\prime}$ state with a planar, four-membered $\mathrm{V}-\mathrm{O}-\mathrm{V}-\mathrm{O}$ ring. Of the six vibrational modes, the three highest in energy $\left(\nu_{\text {scaled }}=835,700\right.$, and $565 \mathrm{~cm}^{-1}$ ) are predicted to be the most intense and therefore they comprise the spectroscopic "fingerprint" of the ring structure. All three of these modes are in-plane deformation modes. The two higher modes match well with the experimental spectrum, while the lowest one lies too low in energy to be observed in our spectra. Note, for the larger cluster ions, starting with $\mathrm{V}_{2} \mathrm{O}_{3}{ }^{+}$, this third band is blueshifted and consequently all three modes comprising the fingerprint are observed in the spectra of the larger species.

A cyclic ${ }^{2} A^{\prime}$ ground state agrees with the previous study of Calatayud et al. ${ }^{20}$ However, the next electronic state is not ${ }^{4} B_{2}$ but ${ }^{6} A^{\prime}$. Due to the weak coupling of $d$ electrons on the two vanadium sites the ${ }^{6} A^{\prime}$ high-spin analogue of ${ }^{2} A^{\prime}$ is
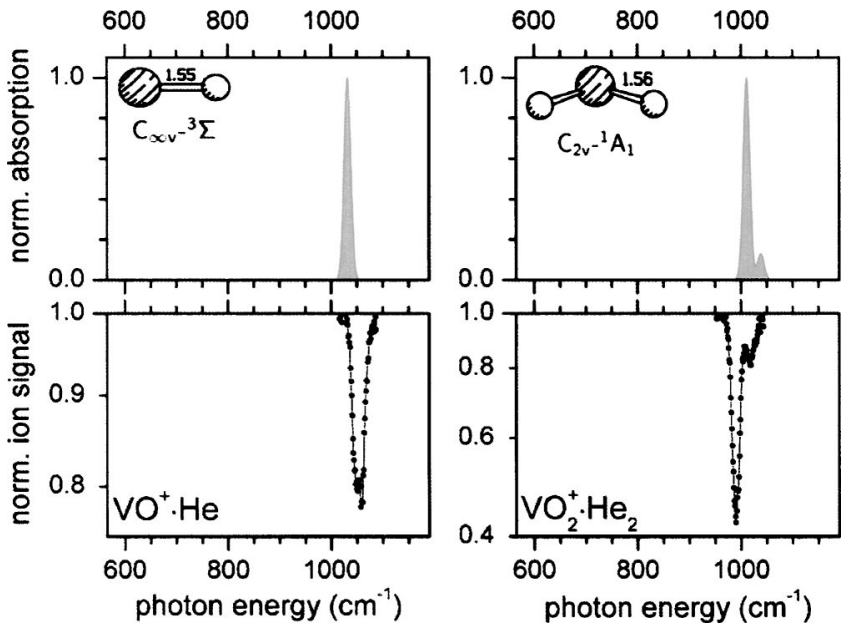

FIG. 2. Simulated IR absorption spectrum (gray line and gray shaded area), based on scaled B3LYP/TZVP frequencies and relative intensities of the ground state (top row) of $\mathrm{VO}^{+}$(left) and $\mathrm{VO}_{2}{ }^{+}$(right) in the region from 565 to $1190 \mathrm{~cm}^{-1}$. Higher resolution, experimental IR photodepletion spectrum (solid black dots connected by black lines) of $\mathrm{VO}^{+} \cdot \mathrm{He}$ (left) and $\mathrm{VO}_{2}{ }^{+} \cdot \mathrm{He}_{2}$ (right) in this energy region are shown in the bottom row. Note the logarithmic scale for the ion signal. 

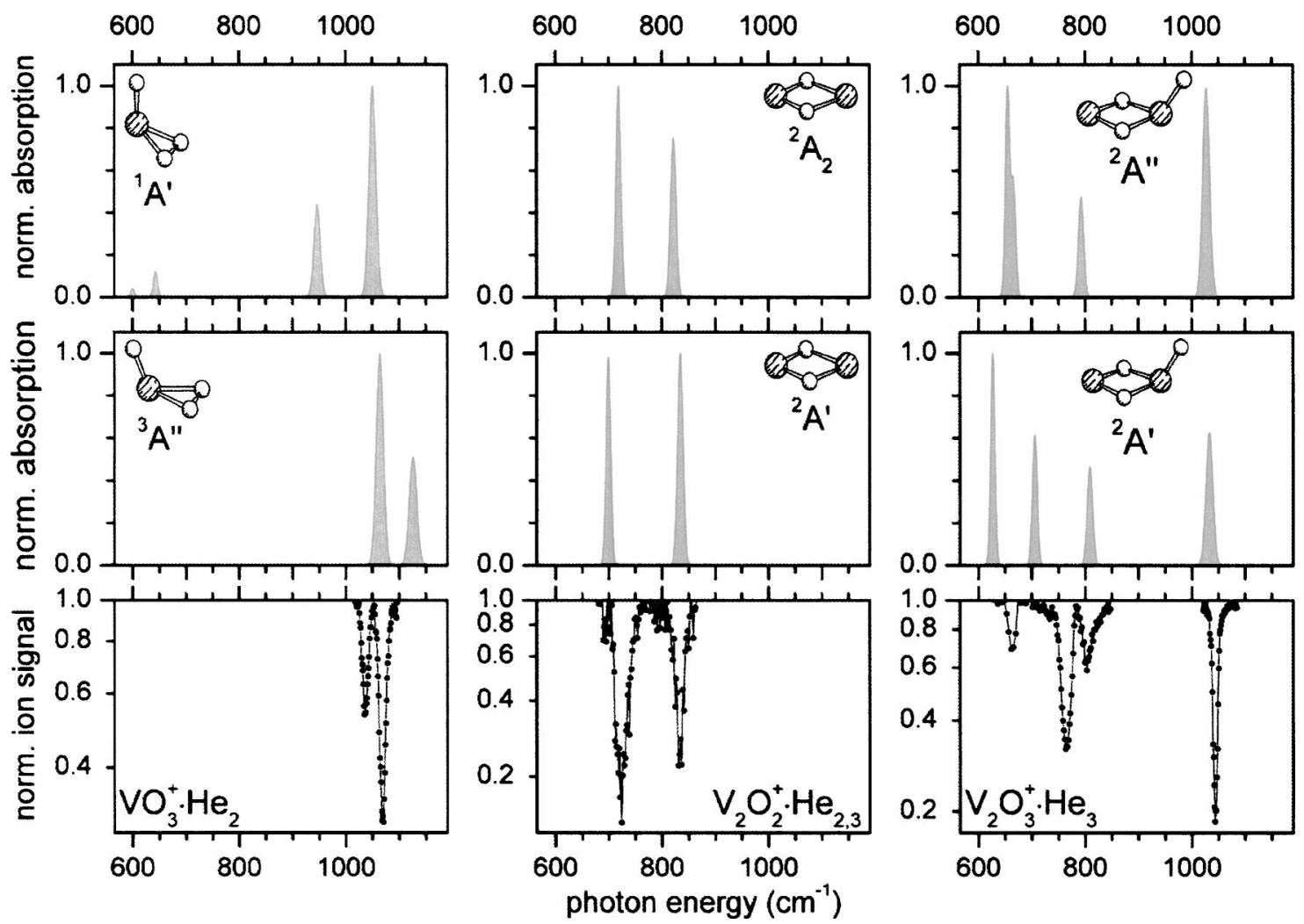

FIG. 3. Simulated IR absorption spectra (gray line and gray shaded area), based on scaled B3LYP/TZVP frequencies and relative intensities of the ground state (middle row) and lowest, electronically excited state (top row), of $\mathrm{VO}_{3}{ }^{+}$(left), $\mathrm{V}_{2} \mathrm{O}_{2}{ }^{+}$(middle), and $\mathrm{V}_{2} \mathrm{O}_{3}{ }^{+}$(right) in the region from 565 to $1190 \mathrm{~cm}{ }^{-1}$. Higher resolution, experimental IR photodepletion spectrum (solid black dots connected by black lines) of $\mathrm{VO}_{3}{ }^{+} \cdot \mathrm{He}_{2}($ left $), \mathrm{V}_{2} \mathrm{O}_{2}{ }^{+} \cdot \mathrm{He}_{2,3}(\mathrm{center})$, and $\mathrm{V}_{2} \mathrm{O}_{3}{ }^{+} \cdot \mathrm{He}_{3}$ (right) in this energy region are shown in the bottom row. Note the logarithmic scale for the ion signal.

only two $\mathrm{kJ} / \mathrm{mol}$ higher in energy and has a virtually identical IR spectrum. $\mathrm{A}^{2} A_{2}$ state $\left(C_{2 v}\right.$ symmetry), with a very similar IR spectrum (see Fig. 3) and slightly better agreement with the experimental spectrum, is found only $10 \mathrm{~kJ} / \mathrm{mol}$ above the ${ }^{2} A^{\prime}$ state. Its high-spin analog, an ${ }^{6} A_{2}$ state, is only $0.2 \mathrm{~kJ} / \mathrm{mol}$ above the ${ }^{2} A_{2}$ state. Therefore an unambiguous assignment of the electronic ground state of $\mathrm{V}_{2} \mathrm{O}_{2}{ }^{+}$requires higher level calculations.

\section{$\mathrm{V}_{2} \mathrm{O}_{3}{ }^{+}$}

The depletion spectrum of $\mathrm{V}_{2} \mathrm{O}_{3}{ }^{+} \cdot \mathrm{He}_{3}$ is shown on the right of Fig. 3. A single, intense band $\left(1044 \mathrm{~cm}^{-1}\right)$ lies in the vanadyl-stretch region. Three additional bands are observed below $810 \mathrm{~cm}^{-1}$, in the $\mathrm{V}-\mathrm{O}-\mathrm{V}-\mathrm{O}$ ring fingerprint region. Consequently, the spectrum supports a ring structure with a single, exocyclic vanadyl group, in contrast to, for example, a linear chain structure, which would reveal two characteristic vanadyl bands. ${ }^{20}$ The experimental spectrum is in reasonable agreement with the IR spectrum of the lowest electronic state $\left({ }^{2} A^{\prime}\right)$ found in our and previous ${ }^{20}$ calculations. In particular, the number and position of the IR active bands are reproduced satisfactorily. The largest discrepancy is observed for the relative intensity of the $666 \mathrm{~cm}^{-1}$ band. The lowest excited state is an ${ }^{2} A^{\prime \prime}$ state, which lies $24.9 \mathrm{~kJ} / \mathrm{mol}$ above the ${ }^{2} A^{\prime}$ state. Its absorption spectrum reveals only three bands plus a shoulder and agrees less well with the observed one.
$\mathrm{V}_{2} \mathrm{O}_{4}{ }^{+}$

The IR photodissociation spectrum of $\mathrm{V}_{2} \mathrm{O}_{4} \cdot \mathrm{He}_{3}$ shows four bands at 1049, 1029, 776, and $594 \mathrm{~cm}^{-1}$ and a pronounced shoulder at $794 \mathrm{~cm}^{-1}$ (see Fig. 4, left). In line with the arguments given above and our calculations for $\mathrm{V}_{2} \mathrm{O}_{4}{ }^{+}$, the three features below $800 \mathrm{~cm}^{-1}$, of which the higher two partially overlap, are attributed to the characteristic modes of the $\mathrm{V}-\mathrm{O}-\mathrm{V}-\mathrm{O}$ ring subunit and the two peaks above 1000 $\mathrm{cm}^{-1}$ are assigned to the symmetric $\left(1049 \mathrm{~cm}^{-1}\right)$ and the antisymmetric $\left(1029 \mathrm{~cm}^{-1}\right)$ combination of the two exocyclic vanadyl groups, with the antisymmetric stretch being the more intense of the two bands. The two vanadyl groups may either occupy cis or trans positions with respect to the ring plane. Note, that a comparison of the relative intensities of all bands would favor an assignment to the cis isomer. However, our B3LYP/TZVP calculations place the cis isomer $19.5 \mathrm{~kJ} / \mathrm{mol}$ higher in energy than the trans isomer. This gap is reduced to $8.4 \mathrm{~kJ} / \mathrm{mol}$, when high-level ab initio calculations (MR-ACPF with basis set extrapolation at the B3LYP geometry) are performed. ${ }^{15}$ Since in $\mathrm{V}_{2} \mathrm{O}_{4}{ }^{+}$the unpaired $d$ electron localizes at one of the $\mathrm{V}$ sites, the $\mathrm{V}-\mathrm{O}-\mathrm{V}-\mathrm{O}$ ring has two long and two short $\mathrm{V}-\mathrm{O}$ bonds. Isomerization into the equivalent structure with the $d$ electron at the other $\mathrm{V}$ site is possible for both the trans and cis structure via a symmetric transition structure ( $C_{2 \mathrm{~h}}$ and $C_{2 v}$ symmetry, respectively) with four identical $\mathrm{V}-\mathrm{O}$ bonds in the ring. ${ }^{15}$ The energy barriers are 19.4 and $21.2 \mathrm{~kJ} / \mathrm{mol}$, respectively. ${ }^{15}$ At suffi- 

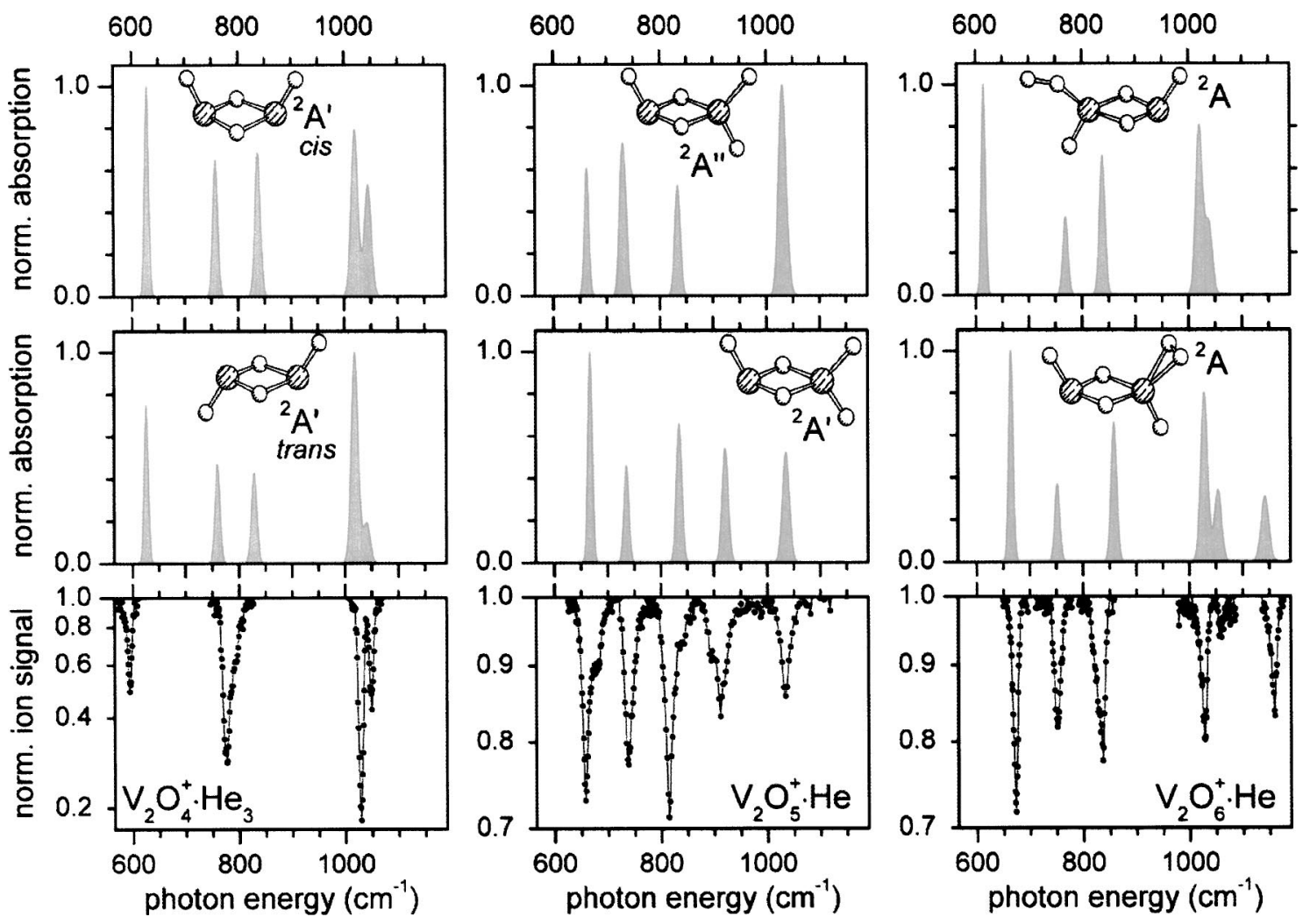

FIG. 4. Simulated IR absorption spectra (gray line and gray shaded area), based on scaled B3LYP/TZVP frequencies and relative intensities of the ground state (middle row) and an energetically low-lying isomer (top row), of $\mathrm{V}_{2} \mathrm{O}_{4}{ }^{+}$(left), $\mathrm{V}_{2} \mathrm{O}_{5}{ }^{+}$(middle), and $\mathrm{V}_{2} \mathrm{O}_{6}{ }^{+}$(right) in the region from 565 to $1190 \mathrm{~cm}{ }^{-1}$. Higher resolution, experimental IR photodepletion spectrum (solid black dots connected by black lines) of $\mathrm{V}_{2} \mathrm{O}_{4}{ }^{+} \cdot \mathrm{He}_{3}$ (left), $\mathrm{V}_{2} \mathrm{O}_{5}{ }^{+} \cdot \mathrm{He}($ center), and $\mathrm{V}_{2} \mathrm{O}_{6}{ }^{+} \cdot \mathrm{He}$ (right) in this energy region are shown in the bottom row. Note the logarithmic scale for the ion signal.

ciently high temperatures large amplitude motions along this isomerization coordinate may affect the predictions for the highest $\left(830 \mathrm{~cm}^{-1}\right)$ and lowest $\left(627 \mathrm{~cm}^{-1}\right)$ of the three characteristic $\mathrm{V}-\mathrm{O}-\mathrm{V}-\mathrm{O}$ ring modes which are due to stretches of the $\mathrm{V}-\mathrm{O}$ bonds in the ring (see Fig. 5).
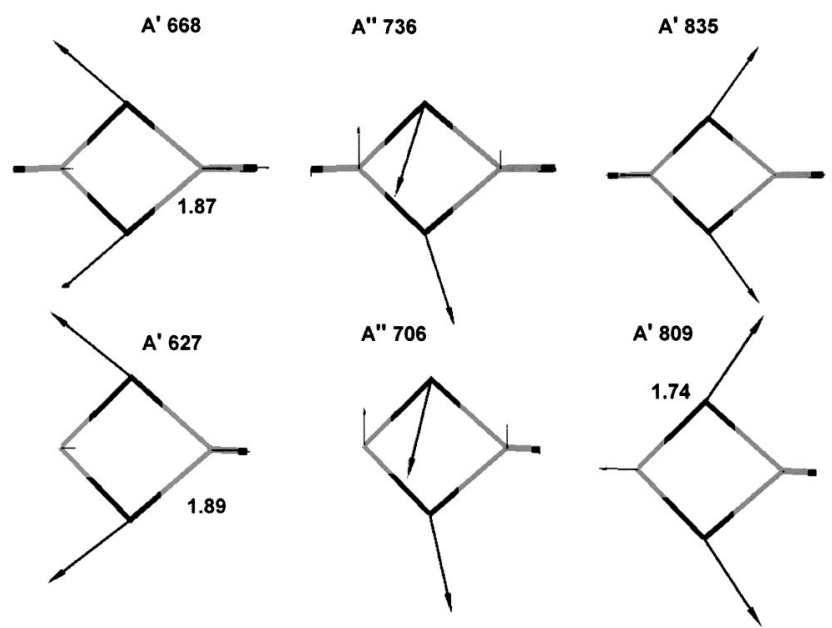

FIG. 5. The three characteristic "in-plane" normal modes of the central $\mathrm{V}-\mathrm{O}-\mathrm{V}-\mathrm{O}$ ring in divanadium oxide cluster cations. The relative motion of the atoms, which is predominantly limited to motion in the plane of the ring, is indicated by the arrows. The scaled B3LYP/TZVP vibrational frequencies are (from left to right) 668,736 , and $835 \mathrm{~cm}^{-1}$ for $\mathrm{V}_{2} \mathrm{O}_{5}{ }^{+}$(top row) and 627 , 706 , and $809 \mathrm{~cm}^{-1}$ for $\mathrm{V}_{2} \mathrm{O}_{3}{ }^{+}$(bottom row).
$\mathrm{V}_{2} \mathrm{O}_{5}{ }^{+}$

The IR photodissociation spectrum of $\mathrm{V}_{2} \mathrm{O}_{5}{ }^{+} \cdot \mathrm{He}$ (Fig. 4 , bottom row, center) shows five bands, two bands in the vanadyl region at 1034 and $911 \mathrm{~cm}^{-1}$ and three, roughly twice as intense bands, below $900 \mathrm{~cm}^{-1}$ at 815,738 , and 657 $\mathrm{cm}^{-1}$. In addition, shoulders are observed at 896,839 , and $679 \mathrm{~cm}^{-1}$. The position, as well as the intensity pattern of the five main peaks, is in excellent agreement with the simulated IR spectrum of the ${ }^{2} A^{\prime}$ state (see Fig. 4), the lowest electronic state we find in our B3LYP/TZVP calculations. Based on these calculations, the $1034 \mathrm{~cm}^{-1}$ band, calculated at $\nu_{\text {scaled }}=1036 \mathrm{~cm}^{-1}$, is assigned to the stretch mode of the isolated vanadyl bond (see Fig. 1). The two geminal V-O bonds form a symmetric and an antisymmetric combination delocalized over both bonds, with scaled frequencies of 922 and $587 \mathrm{~cm}^{-1}$, respectively. The antisymmetric combination is assigned to the $911 \mathrm{~cm}^{-1}$ feature in the experimental spectrum, while the $587 \mathrm{~cm}^{-1}$ band has virtually no intensity (although IR allowed) and is not observed. Similar to the assignments for $\mathrm{V}_{2} \mathrm{O}_{2-4}{ }^{+}$, the remaining three intense bands below $900 \mathrm{~cm}^{-1}$ are attributed to the three characteristic modes of the central $\mathrm{V}-\mathrm{O}-\mathrm{V}-\mathrm{O}$ ring.

The next highest electronic state, calculated $57.1 \mathrm{~kJ} / \mathrm{mol}$ above the ground state, has ${ }^{2} A^{\prime \prime}$ symmetry and geometrical parameters which are similar to those of the ${ }^{2} A^{\prime}$ ground state. The main difference between the two structures is in the length of the longer of the two geminal $\mathrm{V}-\mathrm{O}$ bonds (cis 
position to the isolated $\mathrm{V}-\mathrm{O}$ bond). In the ${ }^{2} A^{\prime}$ state the bond distances for the geminal $\mathrm{V}-\mathrm{O}$ bonds are 170 and $158 \mathrm{pm}$, while in the ${ }^{2} A^{\prime \prime}$ state they are 179 and $156 \mathrm{pm}$. The effect on the IR spectrum is substantial. In contrast to the ${ }^{2} A^{\prime}$ state, the two geminal $\mathrm{V}-\mathrm{O}$ bond stretches do not mix, but remain predominantly localized on the longer and shorter $\mathrm{V}-\mathrm{O}$ bond, and both have appreciable intensity. The scaled frequency of the mode involving the shorter bond is $1030 \mathrm{~cm}^{-1}$, minimally lower than the frequency of the mode involving the isolated vanadyl bond $\left(1038 \mathrm{~cm}^{-1}\right)$. Consequently, the two modes lead to overlapping bands and form a single, intense feature in the simulated spectrum. The scaled frequency of the mode involving the longer $\mathrm{V}-\mathrm{O}$ bond is 728 $\mathrm{cm}^{-1}$ and overlaps with one of the three ring breathing modes $\left(834,736\right.$, and $\left.663 \mathrm{~cm}^{-1}\right)$, effectively increasing the relative intensity of the central feature of this group of three bands. The predicted spectrum of the ${ }^{2} A^{\prime \prime}$ state cannot explain the band observed at $911 \mathrm{~cm}^{-1}$ and we conclude that the calculated B3LYP/TZVP energies and the comparison of the IR spectra provide convincing evidence for an ${ }^{2} A^{\prime}$ and against an ${ }^{2} A^{\prime \prime}$ ground state of $\mathrm{V}_{2} \mathrm{O}_{5}{ }^{+}$. The origin of the observed shoulders is not clear and they are left unassigned. Note, the position of the shoulders does not match the absorption spectrum of the ${ }^{2} A^{\prime \prime}$ excited state discussed above.

\section{$\mathrm{V}_{2} \mathrm{O}_{6}{ }^{+}$}

The IR photodissociation spectrum of $\mathrm{V}_{2} \mathrm{O}_{6}{ }^{+} \cdot \mathrm{He}$ is shown on the right of Fig. 4. Six bands are observed. The band at $1160 \mathrm{~cm}^{-1}$ is too high in energy for a regular vanadyl group and thus is assigned to a superoxo group. The two bands at 1060 and $1028 \mathrm{~cm}^{-1}$ lie in the typical spectral region for vanadyl stretches. Similar to the other spectra of divanadium oxide cluster cations, the three bands at 836, 751 , and $673 \mathrm{~cm}^{-1}$ are attributed to the three characteristic modes of a four-membered $\mathrm{V}-\mathrm{O}-\mathrm{V}-\mathrm{O}$ ring. The experimental spectrum matches exceptionally well with the spectrum calculated for the ${ }^{2} A$ ground state of $\mathrm{V}_{2} \mathrm{O}_{6}{ }^{+}$, and clearly disagrees with the spectrum of the " $\mathrm{O}_{2}$-complex" isomer $\left({ }^{2} A\right)$, found $45.5 \mathrm{~kJ} / \mathrm{mol}$ above the ground state. In the ground state of $\mathrm{V}_{2} \mathrm{O}_{6}{ }^{+}$the two vanadyl groups occupy the trans position and the $\eta^{2}$-superoxo unit forms a threemembered ring with one of the two vanadium atoms (see Fig. 1). The cis isomer is calculated $7.7 \mathrm{~kJ} / \mathrm{mol}$ higher in energy. Its IR spectrum is virtually identical with that of the trans isomer and not shown.

\section{DISCUSSION}

Comparison of the present results with previous multiphoton IR photodissociation studies on metal oxide cations in the region below $2000 \mathrm{~cm}^{-1}$ highlights several important features of the current experimental scheme. (1) In most previous studies on cluster ions and using free electron laser (FEL) radiation the initial ion beam was not mass selected (see, for example, Ref. 39 and references therein) and consequently a mass distribution of cluster ions is irradiated. A mass filter is then used to mass select the "product" ions. Although this method has the multiplex advantage, this procedure does not uniquely identify the signal carrier, because product ions of identical mass can be formed from different parent ions. Unless one has a detailed understanding of the dissociation pathways, mass selection of the ions prior to irradiation is required in order to unambiguously identify the signal carrier. (2) IR photodissociation experiments on bare metal oxide clusters generally require the absorption of multiple IR photons. When multiple isomers are present in the ion beam, the isomer with the lowest dissociation energy, which does not necessarily have to be the thermodynamically most stable one, generally dissociates at the lowest laser fluence and thus is most facile to detect. IR multiphoton dissociation studies on $\mathrm{V}_{4} \mathrm{O}_{10}{ }^{+}$, for example, showed that a $\mathrm{V}_{4} \mathrm{O}_{8}{ }^{+} \cdot \mathrm{O}_{2}$ isomer could be detected, but not the theoretically predicted most stable cage-like isomer of $\mathrm{V}_{4} \mathrm{O}_{10}{ }^{+}$, because the dissociation energy is more than $3 \mathrm{eV}$ higher for the cage structure. ${ }^{10} \mathrm{He}$ tagging reduces the number of photons required in the photodissociation process dramatically, generally down to a single photon, avoiding the complications described above. (3) He tagging also results in a considerable increase of the spectral resolution, because the absorbing species are necessarily the colder subset of the species present in the ion trap, and generally much colder compared to those produced directly by laser vaporization.

The improved experimental scheme combined with the reliable prediction of ground state geometries and frequencies allows for a detailed insight into the structure of metal oxide cluster ions in general and of vanadium oxide cluster cations in this particular study. The central building block of the divanadium oxide cations is a four-membered $\mathrm{V}_{2} \mathrm{O}_{2}$ ring, in which each vanadium atom is adjacent to two oxygen atoms. For one vanadium atom the two $\mathrm{V}-\mathrm{O}$ bonds are significantly shorter than for the other. Experimental evidence for four-membered rings as a structural motif in metal oxide clusters was originally found by von Helden et al. ${ }^{13}$ in their pioneering study on the infrared spectroscopy of neutral zirconium oxide clusters. They observed two very broad absorption bands centered at 620 and $680 \mathrm{~cm}^{-1}$, respectively, and assigned them to vibrational modes of the $\mathrm{Zr}-\mathrm{O}-\mathrm{Zr}-\mathrm{O}$ ring, predicted in the $600-800 \mathrm{~cm}^{-1}$ range. The spectral signature of the $\mathrm{V}-\mathrm{O}-\mathrm{V}-\mathrm{O}$ four-membered ring is three absorption bands of comparable intensity in the region from 550 to $900 \mathrm{~cm}^{-1}$. Both the observed and predicted (in parenthesis) wave numbers fall into narrow ranges of 833-794 (859-809), 776-724 (761-700), 673-594 (668-565) cm $\mathrm{cm}^{-1}$. As the oxygen content increases from $\mathrm{V}_{2} \mathrm{O}_{2}{ }^{+}$to $\mathrm{V}_{2} \mathrm{O}_{6}{ }^{+}$, the number of unpaired $d$ electrons on vanadium sites decreases from $3 / 2$ in $\mathrm{V}_{2} \mathrm{O}_{2}{ }^{+}$to $1 / 0$ in $\mathrm{V}_{2} \mathrm{O}_{6}{ }^{+}$and the number of terminal $\mathrm{VO}$ groups increases from none to $3 . \mathrm{V}_{2} \mathrm{O}_{6}{ }^{+}$includes an additional $\eta^{2}$-superoxo ligand. Neither of these changes affects the characteristic $\mathrm{V}_{2} \mathrm{O}_{2}$ ring modes significantly. Figure 5 sketches the three modes. The highest and the lowest energy modes are couplings of the stretches of the two shorter and longer VO bonds, respectively, with the deformation of the opposite $\mathrm{V}-\mathrm{O}-\mathrm{V}$ angle. Their splitting is indicative of the asymmetry of the $\mathrm{VO}$ bond distances in the ring. The third mode is a $\mathrm{O}-\mathrm{V}-\mathrm{O}$ twist.

The present data can be used to deduce information about $\mathrm{V}-\mathrm{O}$ bond distances of vanadium oxide species, for which the IR spectra (or Raman spectra) are known, but the 


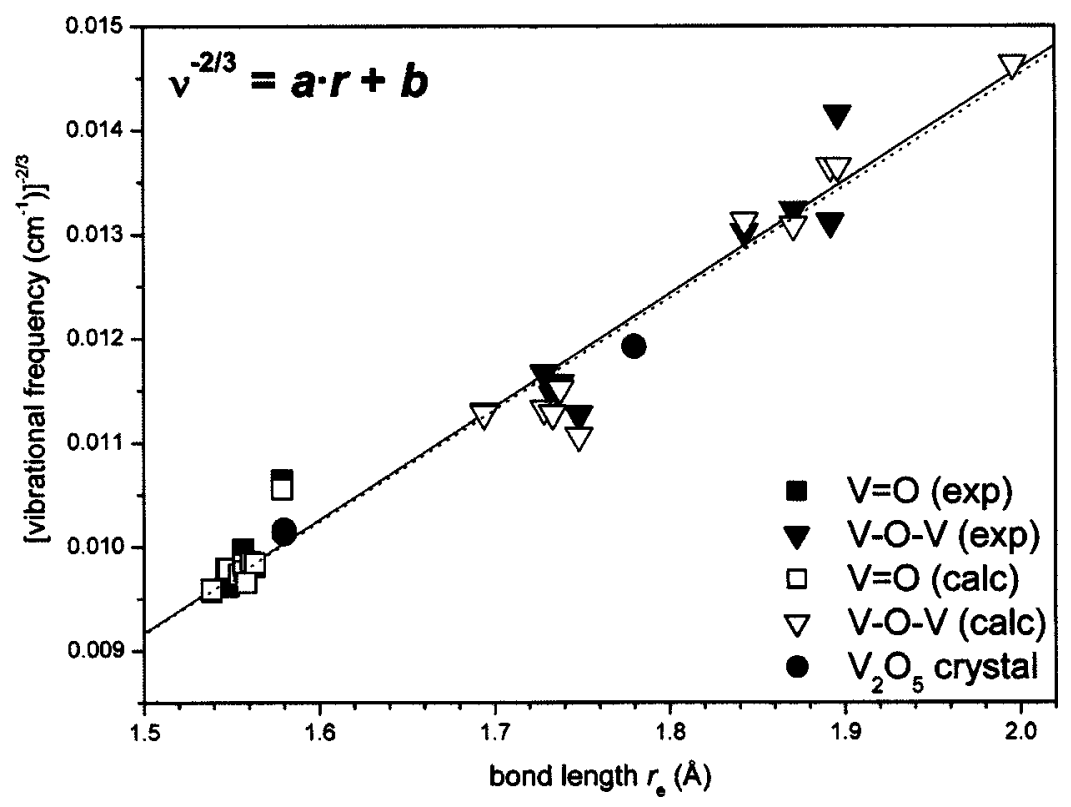

FIG. 6. Badger's rule plot of $\nu^{-2 / 3}$ against the $r_{\mathrm{e}}$, where $\nu$ is the vanadium-oxygen stretching frequency and $r_{\mathrm{e}}$ the vanadium-oxygen bond length. Scaled harmonic (open symbols) and experimental (solid symbols) vibrational frequencies are shown. Squares and triangles refer to gas phase values from the present study and the solid circles are based on previous results on crystalline $\mathrm{V}_{2} \mathrm{O}_{5}$. For the gas phase, data squares indicate frequencies for terminal $\mathrm{V}=\mathrm{O}$ bonds, while triangles represent $\mathrm{V}-\mathrm{O}-\mathrm{V}$ bonds including divalent oxygen atoms. Solid and dotted lines represent the linear, least squares fit to the experimental (gas phase only) and calculated frequencies, respectively.

structure is not. This is relevant for supported vanadium oxide catalysts, and attempts have been made to predict vanadium oxide bond distances for solid materials of unknown structure involving vanadium oxides. ${ }^{40}$ Figure 6 shows that the frequencies of the vanadium-oxygen stretch modes are indeed a monotonic function of the bond distance. Based on the Badger rule, which assumes that for a given bond type the harmonic force constant $k$ is inversely proportional to the cube of the bond distance $r_{\mathrm{e}}, k=C /\left(r_{\mathrm{e}}-d\right)^{3}, \nu^{-2 / 3}$ is plotted against the equilibrium bond distance $r_{\mathrm{e}}$. Both scaled harmonic (open symbols) and experimental (solid symbols) vibrational frequencies are shown. Squares indicate terminal $\mathrm{V}=\mathrm{O}$ bonds, while triangles represent $\mathrm{V}-\mathrm{O}-\mathrm{V}$ bonds including divalent oxygen atoms. Solid and dotted lines represent the linear, least squares fit to the experimental and theoretical frequencies, respectively. The linear fit yields similar values for the experimental $\left(a=0.01086 \mathrm{~cm}^{2 / 3} / \AA, \quad b\right.$ $\left.=0.00713 \mathrm{~cm}^{2 / 3}\right)$ and the theoretical frequencies $(a$

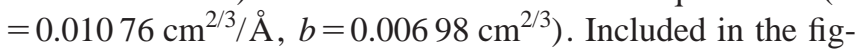
ure are also observed data for $\mathrm{V}=\mathrm{O}$ and $\mathrm{V}-\mathrm{O}(-\mathrm{V})$ bonds of crystalline $\mathrm{V}_{2} \mathrm{O}_{5}$ (solid circles). The observed IR frequencies $\left(981 / 976 \text { and } 768 \mathrm{~cm}^{-1} \text {, respectively }\right)^{41}$ and bond distances (1.58 and $1.78 \AA$, respectively) derived from the $\mathrm{x}$-ray structure $^{42}$ fall on the same line. Hence, use may be made of the present data to derive structure information from IR or Raman spectra of vanadium oxide species supported, for example, on aluminum oxide and silicon dioxide.

Previous theoretical studies had predicted the correct connectivity for most of the clusters, however conflicting assignments for the electronic ground states of $\mathrm{VO}_{3}{ }^{+}$, $\mathrm{V}_{2} \mathrm{O}_{2}{ }^{+}, \mathrm{V}_{2} \mathrm{O}_{4}{ }^{+}, \mathrm{V}_{2} \mathrm{O}_{5}{ }^{+}$, and $\mathrm{V}_{2} \mathrm{O}_{6}{ }^{+}$were made. The assumption of a ${ }^{2} A^{\prime \prime}$ ground state in $\mathrm{V}_{2} \mathrm{O}_{5}{ }^{+}$in Ref. 7 is of particular significance, as many of the reaction energies and also the energy profile shown in Fig. 4 of Ref. 7 will change if the ${ }^{2} A^{\prime}$ ground state found in the present and a previous study $^{21,43}$ is considered. Our calculation of the reaction energies in Table I of Ref. 7 shows that all four reaction energies for $\mathrm{V}_{2} \mathrm{O}_{5}{ }^{+}+\mathrm{C}_{2} \mathrm{H}_{4}$ and two of the reaction energies for
$\mathrm{V}_{2} \mathrm{O}_{6}{ }^{+}+\mathrm{C}_{2} \mathrm{H}_{4}$ change by about $0.6 \mathrm{eV}$. Since the changes for $\mathrm{V}_{2} \mathrm{O}_{5}{ }^{+}$and $\mathrm{V}_{2} \mathrm{O}_{6}{ }^{+}$are in opposite direction, the predicted reactivity differences between the two oxide species become significantly smaller and additional effort is needed to fully understand the observed reaction patterns.

\section{ACKNOWLEDGMENTS}

We thank P. Degelmann (Universität Karlsruhe) for a pre-release version of the aoforce modul which permits unrestricted open shell DFT calculations. This work is supported by the Collaborative Research Center 546 of the Deutsche Forschungsgemeinschaft. The authors thank G. von Helden and A. Fielicke for helpful discussions and gratefully acknowledge the support of the Stichting voor Fundamenteel Onderzoek der Materie (FOM) in providing the required beam time on FELIX and highly appreciate the skillful assistance of the FELIX staff, in particular Dr. A. F. G. van der Meer.

${ }^{1}$ C. N. R. Rao and B. Raven, Transition Metal Oxides (VCH, New York, 1995).

${ }^{2}$ B. M. Weckhuysen and D. E. Keller, Catal. Today 78, 25 (2003).

${ }^{3}$ G. G. Cortez and M. A. Banares, J. Catal. 209, 197 (2002).

${ }^{4}$ D. Schröder, J. Loos, M. Engeser, H. Schwarz, H.-C. Jankowiak, R. Berger, R. Thissen, O. Dutuit, J. Döbler, and J. Sauer, Inorg. Chem. (in press); E. B. Rudnyi, E. A. Kaibicheva, and L. N. Sidorov, J. Chem. Thermodyn. 25, 929 (1993); R. C. Bell, K. A. Zemski, and A. W. Castleman, Jr., J. Phys. Chem. A 102, 8293 (1998); R. C. Bell, K. A. Zemski, and A. W. Castleman, Jr., ibid. 103, 1585 (1999); R. C. Bell, K. A. Zemski, D. R. Justes, and A. W. Castleman, Jr., J. Chem. Phys. 114, 798 (2001); K. A. Zemski, D. R. Justes, and A. W. Castleman, Jr., J. Phys. Chem. A 105, 10237 (2001); A. Dinca, T. P. Davis, K. J. Fisher, D. R. Smith, and G. D. Willett, Int. J. Mass. Spectrom. 182/183, 73 (1999); A. Fielicke and K. Rademann, Phys. Chem. Chem. Phys. 4, 2621 (2002).

${ }^{5}$ H. Wu and L.-S. Wang, J. Chem. Phys. 108, 5310 (1998); H. J. Zhai and L.-S. Wang, ibid. 117, 7882 (2002).

${ }^{6}$ R. C. Bell, K. A. Zemski, K. P. Kerns, H. T. Deng, and A. W. Castlemann, Jr., J. Phys. Chem. A 102, 1733 (1998).

${ }^{7}$ D. R. Justes, R. Mitric, N. A. Moore, V. Bonacic-Koutecký, and A. W. Castleman, Jr., J. Am. Chem. Soc. 125, 6289 (2003).

${ }^{8}$ J. N. Harvey, M. Diefenbach, D. Schröder, and H. Schwarz, Int. J. Mass. Spectrom. 182/183, 85 (1999). 
${ }^{9}$ A. Pramann, K. Koyasu, A. Nakajima, and K. Kaya, J. Chem. Phys. 116, 6521 (2002)

${ }^{10}$ K. R. Asmis, M. Brümmer, C. Kaposta, G. Santambrogio, G. von Helden, G. Meijer, K. Rademann, and L. Wöste, Phys. Chem. Chem. Phys. 4, 1101 (2002).

${ }^{11}$ A. Fielicke, R. Mitric, G. Meijer, V. Bonacic-Koutecky, and G. von Helden, J. Am. Chem. Soc. 125, 15716 (2003).

${ }^{12}$ M. Brümmer, C. Kaposta, G. Santambrogio, and K. R. Asmis, J. Chem. Phys. 119, 12700 (2003).

${ }^{13}$ G. von Helden, A. Kirilyuk, D. van Heijnsbergen, B. Sartakov, M. A. Duncan, and G. Meijer, Chem. Phys. 262, 31 (2000).

${ }^{14}$ O. Hübner and J. Sauer, Phys. Chem. Chem. Phys. 4, 5234 (2002).

${ }^{15} \mathrm{M}$. Pykavy, C. van Wüllen, and J. Sauer, J. Chem. Phys. (to be published).

${ }^{16}$ A. D. Becke, J. Chem. Phys. 98, 5648 (1993).

${ }^{17}$ S. F. Vyboishchikov and J. Sauer, J. Phys. Chem. A 104, 10913 (2000).

${ }^{18}$ S. F. Vyboishchikov and J. Sauer, J. Phys. Chem. A 105, 8588 (2001).

${ }^{19}$ G. K. Koyanagi, D. K. Bohme, I. Kretzschmar, D. Schröder, and H. Schwarz, J. Phys. Chem. A 105, 4259 (2001).

${ }^{20}$ M. Calatayud, B. Silvi, J. Andrés, and A. Beltrán, Chem. Phys. Lett. 333, 493 (2001)

${ }^{21}$ M. Calatayud, J. Andrés, and A. Beltrán, J. Phys. Chem. A 105, 9760 (2001).

${ }^{22}$ J. Sauer and S. F. Vyboishchikov, poster presented at the Berichtskolloquium Sfb 546, Humboldt-Universität zu Berlin, February, 2002 (unpublished).

${ }^{23}$ D. Oepts, A. F. G. van der Meer, and P. W. van Amersfoort, Infrared Phys. Technol. 36, 297 (1995).

${ }^{24}$ R. Ahlrichs, M. Bär, M. Häser, H. Horn, and C. Kölmel, Chem. Phys. Lett. 162, 165 (1989); O. Treuler and R. Ahlrichs, J. Chem. Phys. 102, 346 (1995); K. Eichkorn, O. Treutler, H. Öhm, M. Häser, and R. Ahlrichs, Chem. Phys. Lett. 242, 652 (1995).

${ }^{25}$ A. D. Becke, Phys. Rev. A 38, 3098 (1988).
${ }^{26}$ C. Lee, W. Yang, and R. G. Parr, Phys. Rev. B 37, 785 (1988).

${ }^{27}$ P. J. Stephens, F. J. Devlin, C. F. Chabalowski, and M. J. Frisch, J. Phys. Chem. 98, 11623 (1994).

${ }^{28}$ R. H. Hertwig and W. Koch, Chem. Phys. Lett. 268, 345 (1997).

${ }^{29}$ A. Schäfer, C. Huber, and R. Ahlrichs, J. Chem. Phys. 100, 5829 (1994).

${ }^{30}$ A. J. Wachters, J. Chem. Phys. 52, 1033 (1970).

${ }^{31}$ P. Deglmann, F. Furche, and R. Ahlrichs, Chem. Phys. Lett. 362, 511 (2002).

${ }^{32}$ A. P. Scott and L. Radom, J. Phys. Chem. 100, 16502 (1996).

${ }^{33}$ M. D. Halls, J. Velkovski, and H. B. Schlegel, Theor. Chem. Acc. 105, 413 (2001).

${ }^{34}$ S. A. Nizkorodov, J. P. Maier, and E. J. Bieske, J. Chem. Phys. 103, 1297 (1995); D. Roth, O. Dopfer, and J. P. Maier, Phys. Chem. Chem. Phys. 3, 2400 (2001).

${ }^{35}$ E. J. Bieske and O. Dopfer, Chem. Rev. (Washington, D.C.) 100, 3963 (2000).

${ }^{36}$ J. M. Dyke, B. W. J. Gravenor, M. P. Hastings, and A. Morris, J. Phys. Chem. 89, 4613 (1985)

${ }^{37}$ M. Pykavy and C. van Wüllen, J. Phys. Chem. A 107, 5566 (2003).

${ }^{38}$ J. Harrington and J. C. Weisshaar, J. Phys. Chem. 97, 2809 (1992).

${ }^{39}$ A. Fielicke, G. Meijer, and G. von Helden, J. Am. Chem. Soc. 125, 3659 (2003)

${ }^{40}$ F. D. Hardcastle and I. E. Wachs, J. Phys. Chem. 95, 5031 (1991).

${ }^{41}$ P. Clauws and J. Vennik, Phys. Status Solidi B 76, 707 (1976).

${ }^{42}$ R. Enjalbert and J. Galy, Acta Crystallogr., Sect. C: Cryst. Struct. Commun. 42, 1467 (1986).

${ }^{43}$ Calatayud, Andrés, and Beltrán (Ref. 21) incorrectly label the ground state of $\mathrm{V}_{2} \mathrm{O}_{5}{ }^{+2} A^{\prime \prime}$. However, from the agreement of the bond distances and vibrational frequencies reported in Ref. 21 with our ${ }^{2} A^{\prime}$ results we gather that the state calculated was in fact the correct ${ }^{2} A^{\prime}$ ground state. 